\title{
Agrogenic transformation (degradation) of chernozems of the Central Chernozem Region
}

\author{
K.E. Stekolnikov, E.S. Gasanova, and N.V. Stekolnikova* \\ Voronezh State Agrarian University named after Emperor Peter I, 394087, Voronezh, Russia
}

\begin{abstract}
Modern agriculture is impossible without the use of high balanced doses of mineral fertilizers. Mineral fertilizers in the modern volumes of their application are a powerful anthropogenic factor that increases the level of supply of agricultural crops with nutrients, but did not ensure the stability of yields. The long-term use of high doses of fertilizers does not allow to reach a deficit-free balance of fertilizer elements in agriculture and crop production. Studies of many scientists have shown that the long-term use of mineral fertilizers, in addition to the direct effect, causes a number of side effects, and contributes to the development of pronounced acidification of soils. This effect is observed in all agricultural zones, regardless of soil types. It is more pronounced on initially genetically acidic sod-podzolic and gray forest soils, but also on chernozems, which were considered resistant to acidification development. The consequences of soil acidification are manifested in the mobility and, as a result, the availability of fertilizer elements. Nevertheless, the main effect of soil acidification when using fertilizers is the lack of absorbed bases, which causes their progressive degradation. The acidification effect can be compensated by regular (once per rotation) liming.
\end{abstract}

\section{Introduction}

At the turn of the 20th and 21st centuries, Russian agriculture underwent a radical restructuring, although it should have been about its catastrophic destruction. If starting from the $60 \mathrm{~s}$ of the last century, a course was taken for the chemicalization of agriculture, then the end of this century was accompanied by an almost complete rejection of mineral fertilizers. The latter was primarily due to economic factors, with the current disparity in prices for agricultural products and mineral fertilizers, the use of the latter turned out to be extremely unprofitable. It should also be noted that the hopes placed on mineral fertilizers to increase the yield of agricultural crops were not justified. At the beginning of the 11th five-year plan, the level of application of mineral fertilizers in the regions of the CCR reached $120-160 \mathrm{~kg}$ of r.a./ha. Nevertheless, the yield of the main agricultural crops remained at a low level. The average yield of winter wheat was about $2 \mathrm{t} / \mathrm{ha}$, while the average European yield exceeded $5 \mathrm{t} / \mathrm{ha}$. In modern Europe, the grain yield is 8-12 t/ha. The yield of sugar beet in the USSR remained extremely low, and the global average exceeded

\footnotetext{
* Corresponding author: stekolnikova-nv@mail.ru
} 
$25 \mathrm{t} / \mathrm{ha}$. About a quarter of the farms of the Voronezh region received less than $10 \mathrm{t} / \mathrm{ha}$ of sugar beet, and this is despite the fact that the lion's dose of mineral fertilizers went to sugar beet plantations - over $250 \mathrm{~kg}$ of r.a./ha [1,2].

The generally recognized factor of efficient grain production in the world is the growth of production and use of mineral fertilizers. This factor for a century, i.e. from the beginning of the use of mineral fertilizers in 1880, until 1980, was the determining factor in the growth of agricultural crop yields. In the modern world, the leaders in the use of mineral fertilizers are China, India and the United States. Next are the developed countries of Western Europe - France and Germany, Canada is not far behind them. In India and China, over the past 40 years (as of 2012), the use of mineral fertilizers per unit area has increased 49 and 40 times, respectively. These countries with more than a billion people have become leaders in grain production and have fed their own population. France and Germany produce more grain in total than the huge Russia. In Russia, the use of mineral fertilizers is 12-15 times lower than in the leading countries. In Russia, 2,253 thousand tons of mineral fertilizers were applied (as of 2012), and in France, Germany and Canada, 3,249, 2,253 and 2,770 thousand tons, respectively. In modern Russia, the level of application of mineral fertilizers corresponds to 1961 , i.e. when they began to be used in an amount worthy of mention. Needless to say, the grain yield was also appropriate. If in China it was at the level of $4.69 \mathrm{t} / \mathrm{ha}$, France - 6.92, Germany - $7.47 \mathrm{t} / \mathrm{ha}$ and even in Turkey -2.34 , and in Russia $2.15 \mathrm{t} / \mathrm{ha}$, with a global average of $2.96 \mathrm{t} / \mathrm{ha}$. And this is despite the fact that Russia is one of the leaders in the production of mineral fertilizers. Nevertheless, the country's government prefers to sell them, as well as other natural resources, to the detriment of the economy of own country [2,3].

The useful land areas of Russia are also being reduced under the influence of degradation processes. In general, the dynamics of the qualitative state of the land is characterized by increased acidification, erosion processes, decrease in the amount of nutrients, reduction in humus reserves, and soil salinization. Nevertheless, the greatest problem of modern agriculture in Russia is the progressive acidification of arable soils, including the best ones - chernozems. The level of soil fertility and productivity of agricultural crops is largely determined by soil acidity. We believe that degradation process in chernozems is caused by their decalcification $[4,5,6]$. Calcium losses are caused by a natural process - intra-soil migration under the influence of a downward moisture flow. This process is enhanced and accelerated by acid precipitation and the use of mineral fertilizers, especially physiologically acidic ones. Decalcification is a kind of trigger for the process of soil degradation. Soil acidification is also caused by decalcification.

As follows from the data $[1,2]$, acidic soils make up $50.6 \%$ of the area of the surveyed arable land. In the Belgorod and Voronezh regions, the proportion of soils with high acidity is 34.7 and $30.8 \%$, respectively. In the Kursk, Lipetsk and Tambov regions, they are 68.0, 66.6 and $72.4 \%$, respectively. The soils of these areas need liming. A decade later, the situation has practically not changed, the share of acidic soils in arable land remains high.

The results of arable land monitoring for soil acidity showed that, as of January 1, 2019, in the Russian Federation, out of the surveyed 100.3 million hectares of arable land, acidic soils requiring priority liming occupy $35.0 \%$, or 35.1 million ha; of $2.7 \%$ - strongly and very strongly acidic. In the Russian Federation, soils with the most favorable level of environmental reaction, close to neutral $(\mathrm{pH}$ 5.6-6.0), are distributed on an area of 19.0 million ha, which is $18.9 \%$ of the total surveyed arable land area. Soils characterized by a neutral reaction (pH 6.1-7.5) occupy $30.1 \%$, or 30.2 million ha. Soils with a $\mathrm{pH}$ above 7.5 were determined on an area of 16.0 million hectares, or $16.0 \%$. Among the federal districts of the Russian Federation, the largest areas of arable land in need of liming are located in the Central Federal District (60.7\%). The analysis of the monitoring results of 2018 shows 
that the process of acidification of the soils of the Russian Federation is increasing and the areas of arable land requiring liming are increasing [7].

\section{Objects and methods of research}

Research on the agrogenic transformation of chernozem was carried out in the stationary experience of the Department of Agrochemistry, Soil Science and Agroecology with fertilizers and meliorants, applied in 1987. The soil of the station is leached low-humus low-power heavy-loamy chernozem. The experiment includes 15 options. The research was carried out in the following variants: 1 - absolute control, 2 - control background ( $40 \mathrm{t} / \mathrm{ha}$ of manure), 3 - background $+\mathrm{N}_{60} \mathrm{P}_{60} \mathrm{~K}_{60}, 5$ background $+\mathrm{N}_{120} \mathrm{P}_{120} \mathrm{~K} 120,13$ - background +21 $\mathrm{t} /$ ha of defecate, 15 - background + defecate $+\mathrm{N}_{60} \mathrm{P}_{60} \mathrm{~K}_{60}$. Soil samples were taken in layers to a depth of 1 meter in layers with a step of $20 \mathrm{~cm}$.

Fertilizers were applied according to the experimental scheme, and defecate was last introduced in 2005, so we are observing its aftereffect.

In the soil samples, the following were determined: exchange, actual and hydrolytic acidity. The exchange and actual acidity is determined in a standard extract with a soil: solution ratio $=1: 2.5$ and in saturated soil pastes with a soil: solution ratio $=1: 0.5[3,4]$.

\section{Research results}

The results obtained by us are presented in Tables 2-3 and in Figures 1-3. We evaluated the results considering the existing gradation presented in Table 1.

Table 1. Grouping of soils by degree of acidity and cation exchange capacity.

\begin{tabular}{|c|c|c|c|c|c|}
\hline \multirow{3}{*}{ Soil acidity } & \multicolumn{2}{|c|}{$\mathrm{pH}$} & \multirow{2}{*}{$\begin{array}{c}\text { Hydrolytic } \\
\text { acidity }(\mathrm{Ng}) \text {, }\end{array}$} & \multicolumn{2}{|c|}{ Cation exchange capacity (CEC) } \\
\hline & \multirow{2}{*}{$\mathrm{H}_{2} \mathrm{O}$} & \multirow{2}{*}{ КCl } & & & \\
\hline & & & \multicolumn{2}{|c|}{ mg-eq./100 g of soil } & Level \\
\hline Very strongly acidic & - & $<4$ & $>6$ & $<5.0$ & very low \\
\hline Highly acidic & $3-4$ & $4.1-4.5$ & $5.1-6.0$ & $5.1-15.0$ & low \\
\hline Medium-acidic & $4-5$ & $4.6-5.0$ & $4.1-5.0$ & $15.1-25.0$ & moderately low \\
\hline Slightly acidic & $5-6$ & $5.1-5.5$ & $3.1-4.0$ & $25.1-35.0$ & average \\
\hline Close to neutral & - & $5.6-6.0$ & $2.1-3.0$ & $35.1-45.0$ & moderately high \\
\hline Neutral & 7 & $>6.0$ & $<2.0$ & $>45.0$ & high \\
\hline Slightly alkaline & $7-8$ & - & - & - & - \\
\hline Alkaline & $8-9$ & - & - & - & - \\
\hline Highly alkaline & $9-11$ & - & - & - & - \\
\hline
\end{tabular}

Table 2 shows the results of determining the $\mathrm{pH}$ of an aqueous extract with a standard soil: solution ratio $=1: 2.5$ and in saturated soil pastes with a soil: solution ratio $=1: 0.5$. 
Table 2. Effect of fertilizers and defecate on the $\mathrm{pH}$ value of water and salt extract.

\begin{tabular}{|c|c|c|c|c|c|c|c|c|c|c|c|c|c|}
\hline \multirow[t]{2}{*}{ Variant } & \multirow[t]{2}{*}{ Layer } & \multicolumn{2}{|c|}{$2019, \mathrm{pH}_{\mathrm{vv}}$} & \multicolumn{2}{|c|}{$2020, \mathrm{pH}_{\mathrm{vv}}$} & \multicolumn{2}{|c|}{$2021, \mathrm{pH}_{\mathrm{vv}}$} & \multicolumn{2}{|c|}{$2019, \mathrm{pH}_{\text {salt }}$} & \multicolumn{2}{|c|}{$2020, \mathrm{pH}_{\text {salt }}$} & \multicolumn{2}{|c|}{$2021, \mathrm{pH}_{\text {salt }}$} \\
\hline & & $1: 2.5$ & $1: 0.5$ & $1: 2.5$ & $1: 0.5$ & $1: 2.5$ & $1: 0.5$ & $1: 2.5$ & $1: 0.5$ & $1: 2.5$ & $1: 0.5$ & $1: 2.5$ & $1: 0.5$ \\
\hline \multirow[t]{2}{*}{ Contr. } & $0-20$ & 6.73 & 5.80 & 6.31 & 6.21 & 6.30 & 6.01 & 5.24 & 4.63 & 5.85 & 5.03 & 4.83 & 4.54 \\
\hline & $20-40$ & 6.68 & 6.03 & 6.17 & 5.98 & 6.24 & 6.03 & 5.63 & 5.07 & 5.43 & 4.87 & 4.81 & 4.62 \\
\hline \multirow[t]{2}{*}{ Background org. } & $0-20$ & 7.00 & 5.91 & 6.04 & 5.80 & 6.24 & 6.03 & 5.75 & 4.64 & 5.18 & 4.70 & 4.88 & 4.62 \\
\hline & $20-40$ & 6.77 & 5.99 & 6.88 & 5.75 & 6.31 & 6.05 & 5.43 & 4.97 & 5.21 & 4.72 & 4.74 & 4.62 \\
\hline \multirow[t]{2}{*}{ Background+1NPK } & $0-20$ & 6.77 & 6.08 & 5.79 & 5.53 & 6.15 & 5.94 & 5.98 & 4.80 & 4.91 & 4.46 & 4.66 & 4.43 \\
\hline & $20-40$ & 6.68 & 5.99 & 6.07 & 5.74 & 6.36 & 6.17 & 5.88 & 5.09 & 5.08 & 4.64 & 4.79 & 4.57 \\
\hline \multirow[t]{2}{*}{ Background $+2 \mathrm{NPK}$} & $0-20$ & 6.88 & 5.50 & 5.78 & 5.38 & 5.92 & 5.59 & 5.33 & 4.60 & 4.68 & 4.26 & 4.36 & 4.15 \\
\hline & $20-40$ & 6.67 & 5.86 & 5.86 & 5.58 & 6.34 & 5.97 & 5.36 & 4.78 & 4.99 & 4.59 & 4.93 & 4.60 \\
\hline \multirow[t]{2}{*}{ Background+def. } & $0-20$ & 7.19 & 6.44 & 6.69 & 6.40 & 6.89 & 6.65 & 6.87 & 5.36 & 5.89 & 5.38 & 5.52 & 5.32 \\
\hline & $20-40$ & 7.21 & 6.49 & 6.87 & 6.54 & 6.97 & 6.74 & 6.41 & 5.24 & 5.98 & 5.53 & 5.52 & 5.34 \\
\hline \multirow[t]{2}{*}{ Def.+1NPK } & $0-20$ & 6.69 & 5.89 & 6.66 & 6.19 & 6.55 & 6.21 & 6.03 & 4.81 & 5.92 & 5.21 & 5.58 & 5.33 \\
\hline & $20-40$ & 6.64 & 6.13 & 6.53 & 6.15 & 6.56 & 6.26 & 5.76 & 5.13 & 5.83 & 5.27 & 5.47 & 5.37 \\
\hline \multicolumn{2}{|l|}{$\mathrm{S}, \%$} & 3.52 & 3.33 & 3.33 & 2.36 & 3.44 & 2.44 & 3.10 & 2.64 & 4.25 & 4.08 & 3.59 & 2.92 \\
\hline \multicolumn{2}{|l|}{$\mathrm{LSD}_{095}$} & 0.24 & 0.20 & 0.21 & 0.14 & 0.22 & 0.15 & 0.18 & 0.13 & 0.23 & 0.20 & 0.18 & 0.14 \\
\hline
\end{tabular}

As follows from the data in Table 2, the $\mathrm{pH}$ value determined in the standard extract is significantly higher than in saturated soil pastes. The maximum differences are observed in 2019 and are $0.93,1.09,0.69,1.38,0.75$ and 0.80 in the arable layer, respectively, according to the experimental variants. It should be noted that in 2019 , the field was under a sugar beet crop, which is very sensitive to media reaction. In 2020, the field was under vico-oat mixture, and in 2021 under winter wheat. Without any doubt, the $\mathrm{pH}$ value of the water extract was influenced not only by fertilizers and defecate, but also by cultivated crops. If the sugar beet root system can spread to a depth of 3 meters, then winter wheat has the bulk of the roots in a layer of $50-120 \mathrm{~cm}$. winter vetch has a taproot that penetrates to a depth of $2.5 \mathrm{~m}$, and a well-developed network of small roots. The main mass of the roots is located at a depth of $0-15 \mathrm{~cm}$. Therefore, it does not tolerate the soil desiccation. It develops well on neutral soils.

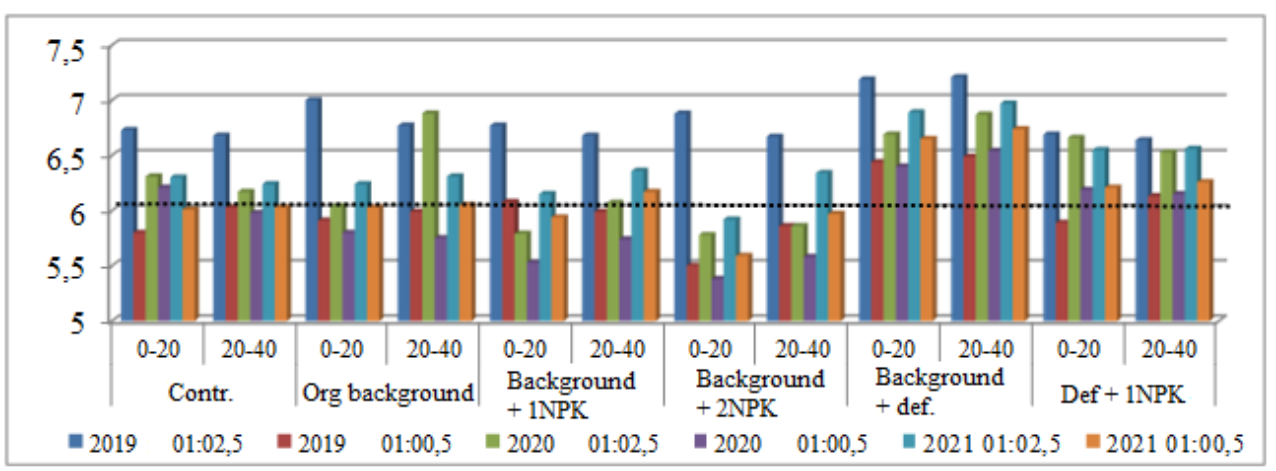

Fig. 1. The effect of fertilizers and defecate on the $\mathrm{pH}$ value of the water extract. 
The green line marks the pH 6 level corresponding to the neutral reaction of the media. According to the existing classification by the $\mathrm{pH}$ value of the water extract in the arable layer, the range 5-6 is slightly acidic. As follows from the data in Table 2 and Figure 1, there is some contradiction between the $\mathrm{pH}$ data in the standard extract and in saturated soil pastes. According to the $\mathrm{pH}$ value of the standard extract in 2019, the reaction of the medium is neutral on all variants of the experiment. In 2020, the reaction of the media is slightly acidic on the variants of the organo-mineral fertilizer system, and in 2021 it remains so only on the variant of the organo-mineral fertilizer system with a double dose of mineral fertilizers. We consider that saturated soil pastes give more objective results in determining the actual acidity.

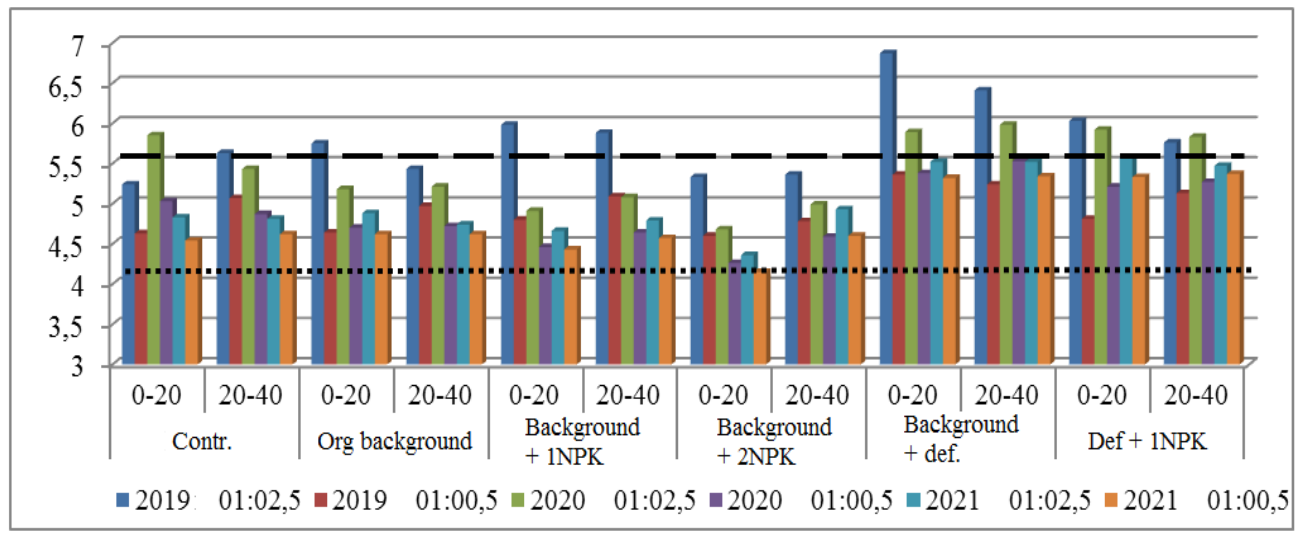

Fig. 2. The effect of fertilizers and defecate on the $\mathrm{pH}$ value of the salt extract.

It was found that according to the $\mathrm{pH}$ value of the standard water extract, acidification, insignificant one, is detected only on the variants of the organo-mineral fertilizer system. As we have already noted, in the standard extract, the $\mathrm{pH}$ value is significantly overestimated due to the very high dilution of the soil solution, since the determination is performed at $250 \%$ soil moisture.

This pattern, which we have identified, is also confirmed for the $\mathrm{pH}$ of the salt extract according to the data obtained (see Table 2, Fig. 2). The lines highlight the range from a strong to a weak acidic reaction. As follows from the data in Table 2 and Figure 2, the differences in the $\mathrm{pH}$ value of the standard salt extract and in saturated soil pastes are significant, and its level is lower than that of the water extract. Nevertheless, in the variants with the defecate aftereffect, it is higher than in the control and fertilized variants. If the $\mathrm{pH}$ of the standard salt extract corresponds to a neutral and slightly acidic range in the control and fertilized versions, then in saturated pastes it is mainly strongly and medium acidic. It is slightly acidic or neutral only on variants with a defecate.

Table 3 shows the results of determining the hydrolytic acidity and the sum of the exchange bases. 
Table 3. Effect of fertilizers and defecate on the value of hydrolytic acidity, the sum of exchange bases

\begin{tabular}{|c|c|c|c|c|c|c|c|}
\hline Variant & Layer & $\mathrm{Ng}, 2019$ & $\mathrm{Ng}, 2020$ & $\mathrm{Ng}, 2021$ & $\mathrm{~S}, 2019$ & $\mathrm{~S}, 2020$ & $\mathrm{~S}, 2021$ \\
\hline \multirow{3}{*}{ Contr. } & $0-20$ & 3.33 & 2.07 & 4.14 & 19.27 & 19.62 & 20.49 \\
\cline { 2 - 8 } & $20-40$ & 2.07 & 2.21 & 4.42 & 21.55 & 20.07 & 19.99 \\
\hline \multirow{3}{*}{ Background org. } & $0-20$ & 2.57 & 2.57 & 4.42 & 19.40 & 19.90 & 18.72 \\
\cline { 2 - 8 } & $20-40$ & 1.78 & 3.56 & 4.71 & 22.77 & 17.00 & 19.62 \\
\hline Background+1NPK & $0-20$ & 2.57 & 4.05 & 4.71 & 19.52 & 19.82 & 18.77 \\
\cline { 2 - 8 } & $20-40$ & 1.74 & 3.05 & 4.52 & 21.17 & 20.50 & 20.14 \\
\hline Background+2NPK & $0-20$ & 3.63 & 4.61 & 5.73 & 19.57 & 19.10 & 18.77 \\
\cline { 2 - 8 } & $20-40$ & 2.16 & 3.82 & 4.92 & 22.35 & 17.25 & 20.34 \\
\hline Background+def. & $0-20$ & 1.40 & 1.86 & 3.48 & 21.90 & 21.92 & 20.90 \\
\cline { 2 - 8 } & $20-40$ & 1.67 & 1.40 & 3.33 & 21.55 & 21.17 & 20.44 \\
\hline Def.+1NPK & $0-20$ & 2.46 & 2.25 & 3.82 & 21.55 & 18.75 & 19.87 \\
\cline { 2 - 8 } & $20-40$ & 2.02 & 2.07 & 4.14 & 20.65 & 21.00 & 19.06 \\
\hline \multicolumn{2}{|c|}{ S, \% } & 3.93 & 3.58 & 3.44 & 4.87 & 4.76 & 4.60 \\
\hline \multicolumn{2}{|c|}{ LSD 095} & 0.27 & 0.30 & 0.45 & 0.31 & 0.30 & 0.27 \\
\hline
\end{tabular}

As follows from the data obtained by us, the value of hydrolytic acidity is very dynamic both according to the years of observations and according to the experiment variants. Nevertheless, the general pattern is its increase on fertilized variants and decrease on variants with defecate aftereffect in relation to the control. These results are most clearly presented in Figure 3.

The line marks the level of $2 \mathrm{mg}$.-eq/100 $\mathrm{g}$ of soil and below, corresponding to neutral soil. As follows from the data in Table 3 and Figure 3, such a level of hydrolytic acidity in the arable layer is observed only in the variant with a defecate for organic background in 2019 and 2020. In 2021, the maximum value of hydrolytic acidity is observed in all variants of the experiment, which is due to heavy precipitation of a prolonged and cool spring and intensive leaching of carbonates from the upper part of the profile of the studied soil. In fact, more than $300 \mathrm{~mm}$ of precipitation fell in March-May of this year, i.e. more than half of the annual norm. Nevertheless, the level of hydrolytic acidity on the variants with defecate is significantly lower than on the control and fertilized variants.

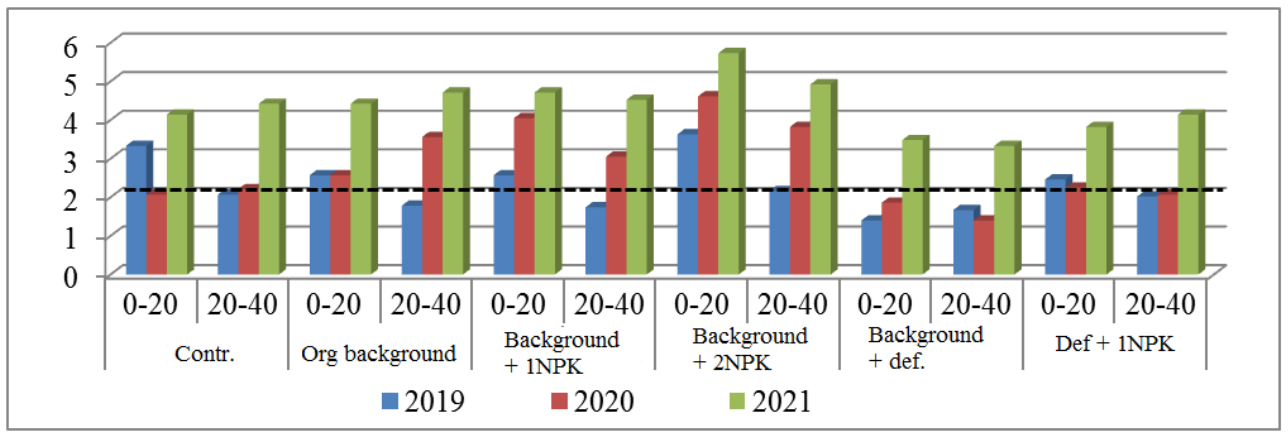

Fig. 3. The effect of fertilizers and defecate on the value of hydrolytic acidity, mg.- eq/100 $\mathrm{g}$ of soil.

It is believed that the amount of exchange bases in soils is quite stable and is not subject to changes. This take place, but only in virgin soils. In arable soils under the influence of fertilizers and meliorants, the amount of exchange bases is quite dynamic, which is confirmed by our data (Table 3, Fig. 4). 


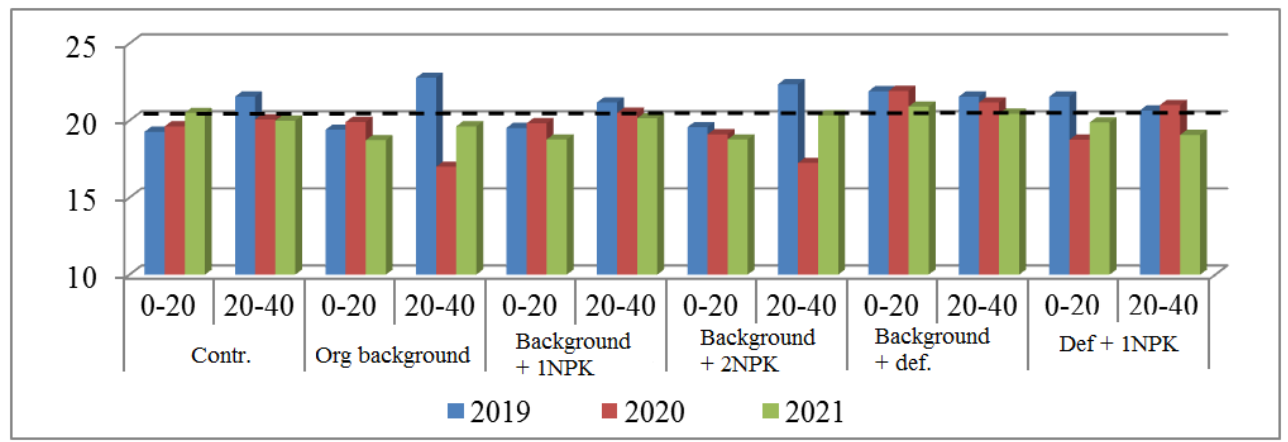

Fig. 4. The effect of fertilizers and defecate on the amount of exchange bases, mg.-eq/100 $\mathrm{g}$ of soil.

The sum of the exchange bases is determined by the combination of mineral, organic and organo-mineral colloids, i.e. from the soil absorbing complex (SAC). The amount of colloids is determined by the granulometric, mineralogical composition and organic matter of the soil. In turn, this complex is affected by the media reaction. Acidification reduces, and alkalinization increases the number of active centers in the SAC. That is why special attention should be paid to the soil acidity regime, since it can be regulated by the simplest method - liming.

As follows from the data in Figure 4, the most stable level of the sum of the exchange bases is observed only in the variant with defecate aftereffect on the organic background. The control variant is as close to this level as possible, and it is lower for all variants with fertilizers, including the variant with defecate aftereffect together with a single dose of mineral fertilizers.

The cation exchange capacity (CEC) is determined by the sum of the exchange bases and hydrolytic acidity. The data is shown in Table 4. According to the gradation (see Table 1) the CEC value of $15.1-25.0 \mathrm{mg}$.-eq/100 $\mathrm{g}$ of soil is estimated as moderately low. As follows from the data in Table 4, in all variants of the experiment for all years of observation, the CEC remains within this gradation.

Table 4. The effect of fertilizers and defecate on the cation exchange capacity (CEC) and the degree of saturation with bases $(\mathrm{V}, \%)$.

\begin{tabular}{|c|c|c|c|c|c|c|c|}
\hline Variant & Layer & 2019 & 2020 & 2021 & 2019 & 2020 & 2021 \\
\hline \multirow{2}{*}{ Contr. } & $0-20$ & 20.60 & 21.69 & 24.63 & 85 & 90 & 83 \\
\cline { 2 - 8 } & $20-40$ & 23.62 & 22.28 & 24.41 & 91 & 93 & 82 \\
\hline Background org. & $0-20$ & 21.97 & 22.47 & 23.14 & 88 & 89 & 81 \\
\cline { 2 - 8 } & $20-40$ & 24.55 & 20.56 & 24.33 & 93 & 83 & 81 \\
\hline Background+1NPK & $0-20$ & 22.09 & 23.87 & 23.48 & 88 & 83 & 80 \\
\cline { 2 - 8 } & $20-40$ & 22.91 & 23.55 & 24.66 & 92 & 87 & 82 \\
\hline Background+2NPK & $0-20$ & 23.20 & 23.71 & 24.50 & 84 & 81 & 77 \\
\cline { 2 - 8 } & $20-40$ & 24.51 & 21.07 & 25.27 & 91 & 82 & 80 \\
\hline Background+def. & $0-20$ & 23.30 & 23.78 & 24.38 & 94 & 92 & 86 \\
\cline { 2 - 8 } & $20-40$ & 23.22 & 22.57 & 23.77 & 94 & 94 & 86 \\
\hline Def.+1NPK & $0-20$ & 24.01 & 21.00 & 23.69 & 90 & 89 & 84 \\
\cline { 2 - 8 } & $20-40$ & 22.67 & 23.07 & 23.20 & 91 & 91 & 82 \\
\hline
\end{tabular}

As follows from the data in Table 4, the CEC varies slightly according to the variants of the experiment, especially in the $0-20 \mathrm{~cm}$ layer. It would seem that we can conclude that there is no obvious advantage of variants with a defecate in this indicator. But this is not 
quite true. This is most clearly shown in Figure 5.

First of all, using the data of Figure 5, we note that in the fertilized variants, the CEC value is very dynamic, but in the variant with the aftereffect of defecate on the organic background, it is the most stable. The high CEC values on the fertilized variants are explained by a significant proportion of hydrolytic acidity. This is confirmed by the data on the degree of saturation of the bases (see Table 4 and Fig. 6).

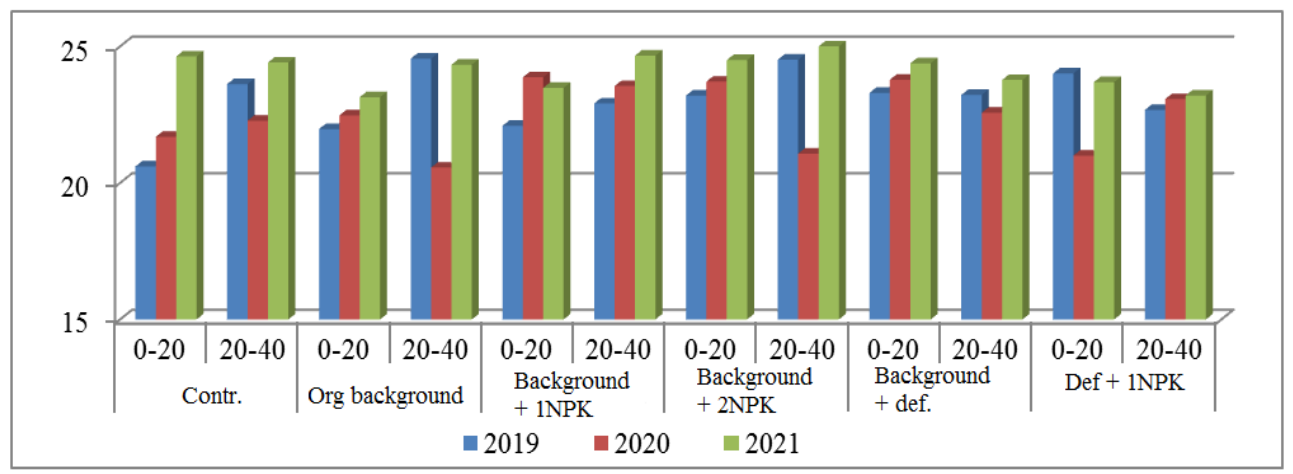

Fig. 5. The effect of fertilizers and defecate on the cation exchange capacity, mg.-eq/100 g of soil

In Figure 6, the dashed line is drawn at the level of 93\%, according to [], with the degree of saturation of bases in the arable layer below $93 \%$, the chernozem needs liming. The dashed line at the level of $80 \%$ shows the critical level of the degree of saturation of bases for chernozems. This level will be reached only in 2021 in the arable layer of variants of the organo-mineral fertilizer system with a single and double dose of mineral fertilizers.

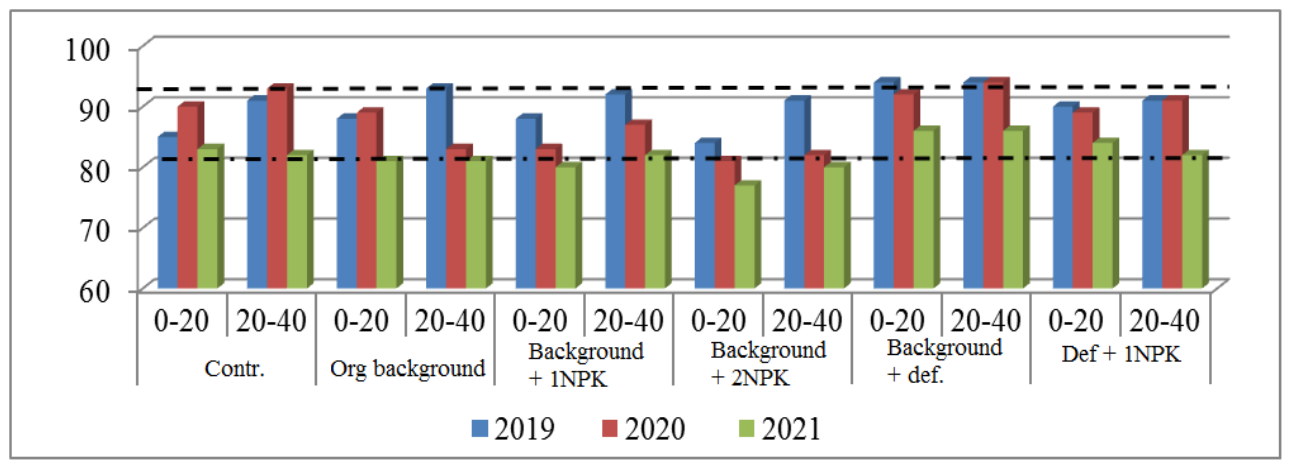

Fig. 6. The effect of fertilizers and defecate on the degree of saturation with bases, $\%$.

It should be noted that only in the variant with the defecate aftereffect on the organic background in 2019, the level of $93 \%$ was exceeded. The data obtained by us allow to conclude that in intensive crop rotations, regular liming is necessary - once per crop rotation.

Our research has established that the actual, exchange and especially hydrolytic acidity affect the state of the SAC of the studied soil. This conclusion is based on the calculation of the correlation coefficients between the acidity indicators with the sum of the exchange bases and the CEC. The data is presented in Table 5. 
Table 5. Correlation coefficients.

\begin{tabular}{|c|c|c|c|c|c|c|c|c|c|c|c|}
\hline \multirow{2}{*}{$\begin{array}{c}\text { Variants } \\
\text { of } \\
\text { experime } \\
\text { nt }\end{array}$} & \multirow[t]{2}{*}{$\begin{array}{c}\text { Layer, } \\
\mathrm{cm}\end{array}$} & \multirow{2}{*}{$\begin{array}{c}\mathrm{pH}_{\mathrm{v}} \\
1: 2,5 \\
\mathrm{~S}\end{array}$} & \multirow{2}{*}{$\begin{array}{c}\mathrm{pH}_{\mathrm{v}} \\
1: 0,5 \\
\mathrm{~S}\end{array}$} & \multirow{2}{*}{$\begin{array}{c}\mathrm{pH}_{\mathrm{v}} \\
1: 2,5 \\
\mathrm{CEC}\end{array}$} & \multirow{2}{*}{$\begin{array}{c}\mathrm{pH}_{\mathrm{v}} \\
1: 0,5 \\
\mathrm{CEC}\end{array}$} & \multirow{2}{*}{$\begin{array}{c}\mathrm{pH}_{\mathrm{s}} \\
1: 2,5 \\
\mathrm{~S}\end{array}$} & \multirow{2}{*}{$\begin{array}{c}\mathrm{pH}_{\mathrm{s}} \\
1: 0,5 \\
\mathrm{~S}\end{array}$} & \multirow{2}{*}{$\begin{array}{c}\mathrm{pH}_{\mathrm{s}} \\
1: 2,5 \\
\mathrm{CEC}\end{array}$} & \multirow{2}{*}{$\begin{array}{c}\mathrm{pH}_{\mathrm{s}} \\
1: 0,5 \\
\mathrm{CEC}\end{array}$} & \multicolumn{2}{|c|}{$\mathrm{Ng}$} \\
\hline & & & & & & & & & & S & CEC \\
\hline \multirow{2}{*}{ Contr. } & $0-20$ & 0.720 & 0.292 & 0.708 & 0.275 & -0.607 & -0.403 & -0.621 & -0.419 & -0.597 & 0.611 \\
\hline & $20-40$ & 0.985 & 0.460 & 0.271 & 0.930 & 0.721 & 0.857 & -0.616 & -0.426 & -0.583 & 0.749 \\
\hline \multirow{2}{*}{$\begin{array}{c}\text { Backgrou } \\
\text { nd org. }\end{array}$} & $0-20$ & -0.111 & -0.998 & -0.692 & 0.827 & 0.421 & 0.933 & 0.966 & -0.320 & -0.906 & 0.905 \\
\hline & $20-40$ & -0.130 & 0.720 & -0.611 & 0.971 & 0.362 & 0.731 & -0.156 & 0.285 & -0.644 & -0.172 \\
\hline \multirow{2}{*}{$\begin{array}{c}\text { Backgrou } \\
\text { nd+1NP } \\
\mathrm{K} \\
\end{array}$} & $0-20$ & 1.129 & .529 & -0.987 & 0.831 & 0.409 & .310 & 0.925 & 0.960 & 0.5 & .870 \\
\hline & $20-40$ & 0.662 & -0.255 & -0.388 & 0.551 & 0.996 & 0.974 & -0.914 & -0.850 & -0.979 & 0.993 \\
\hline \multirow{2}{*}{$\begin{array}{c}\text { Backgrou } \\
\text { nd }+2 \mathrm{NP} \\
\mathrm{K}\end{array}$} & $0-20$ & 0.858 & .334 & -0.722 & 0.535 & -0.937 & 0.983 & 0.950 & -0.917 & -0.990 & 0.996 \\
\hline & $20-40$ & $\begin{array}{l}0.999 \\
\end{array}$ & 0.778 & 0.832 & $\begin{array}{l}0.994 \\
\end{array}$ & 0.715 & 0.826 & 0.222 & 0.389 & -0.496 & 0.054 \\
\hline \multirow{2}{*}{$\begin{array}{l}\text { Backgrou } \\
\text { nd+def. }\end{array}$} & $0-20$ & 0.098 & -0.991 & -0.543 & 0.820 & 0.670 & 0.950 & -0.949 & -0.702 & -0.974 & 0.969 \\
\hline & $20-40$ & 0.545 & -0.988 & 0.332 & 0.724 & 0.987 & -0.165 & -0.475 & -0.681 & -0.890 & 0.904 \\
\hline \multirow{2}{*}{$\begin{array}{c}\text { Def.+1N } \\
\text { PK }\end{array}$} & $0-20$ & 0.314 & -0.894 & -0.220 & -0.535 & 0.344 & -0.807 & -0.189 & -0.388 & 0.008 & 0.523 \\
\hline & $20-40$ & 0.086 & -0.951 & -0.875 & 0.786 & 0.999 & -0.704 & -0.545 & 0.982 & -0.982 & 0.705 \\
\hline
\end{tabular}

As follows from the data in Table 5, there is a direct and inverse relation between the indicators of actual and exchange acidity and the sum of exchange bases, from average to close. The same relation is established with the value of the cation exchange capacity.

Based on the data given in the table above it follows that there is a direct feedback between the hydrolytic acidity and the sum of the exchange bases, from medium to close. There is a direct relation between hydrolytic acidity and CEC, from medium to close.

\section{Conclusions}

Progressive acidification of chernozem is accompanied by a significant restructuring of the soil absorbing complex. The proportion of absorbed calcium decreases, and the proportion of hydrolytic acidity increases, the degree of saturation with bases decreases sharply.

The defecate aftereffect on the organic background largely compensates for progressive acidification and stabilizes the soil absorbing complex.

The data obtained by us allow to conclude that in intensive crop rotations, regular liming is necessary - once per crop rotation.

An average and close relation of hydrolytic acidity with the cation exchange capacity and a negative medium and close relation with the sum of exchange bases was established.

\section{References}

1. Report on the state and use of agricultural land in the Russian Federation in 2018, Moscow, 337 (2020)

2. Report on the state and use of agricultural land, Moscow, 100 (2010)

3. K.E. Stekolnikov, Carbonate-calcium regime and humus state of chernozomes of the forest-steppe of the CCD, 47 (Voronezh, Voronezh SAU, 2011)

4. D.N. Lipatov, A.I. Shcheglov, D.V. Manakhov, P.T. Brekhov, Soil Science 2, 211-223 (2021)

5. V.V. Kotov, K.E. Stekolnikov, S.V. Tkachenko, S.V. Martynenko, E.S. Gridyaeva, Soil Science 6, 713-718 (2004) 
6. V.V. Kotov, D.V. Nenakhov, E.S. Gasanova, K.E. Stekolnikov, Sorption and chromatographic processes 10 (1), 47-53 (2010)

7. E.S. Gasanova, A.N. Kozhokina, N.G. Myazin, K.E. Stekolnikov, IOP Conference Series: Earth and Environmental Science, 012122 (2020) 